\title{
Study of Psychological Resilience among Health Care Professionals, in Ibn Sina Hospital/Rabat/Morocco
}

\section{Hassan Chtibi' ${ }^{1}$, Ahmed Ahami1 ${ }^{1}$, Fatima Zahra Azzaoui ${ }^{1}$, Abderezzak Khadmaoui², Khaoula Mammad' ${ }^{\text {, Farid Elmassioui }}{ }^{3}$}

${ }^{1}$ Unit of Clinical and Cognitive Neuroscience and Nutritional Health, Department of Biology,

Faculty of Science, Kenitra, Morocco

${ }^{2}$ Genetics and Biometrics Laboratory, Faculty of Sciences, Kenitra, Morocco

${ }^{3}$ Human and Artificial Cognition (HAC), Psychology UFR, Paris 8 University, Paris, France

Email: has.chtibi@gmail.com

How to cite this paper: Chtibi, H., Ahami, A., Azzaoui, F.Z., Khadmaoui, A., Mammad, K. and Elmassioui, F. (2018) Study of Psychological Resilience among Health Care Professionals, in Ibn Sina Hospital/Rabat/ Morocco. Open Journal of Medical Psychology, 7, 47-57.

https://doi.org/10.4236/ojmp.2018.73005

Received: May 16, 2018

Accepted: July 7, 2018

Published: July 10, 2018

Copyright $(9) 2018$ by authors and Scientific Research Publishing Inc. This work is licensed under the Creative Commons Attribution International License (CC BY 4.0).

http://creativecommons.org/licenses/by/4.0/

\begin{abstract}
Psychological resilience is the ability to maintain personal and professional wellbeing in the face of on-going work stress and adversity. The aim is to investigate the state of the psychological resilience of Health Care Professionals (HCP) and the potential risk factors. The study that we conducted carries out a sample of 230 persons ( 150 nurses and 80 doctors) belonging to the different services of Ibn Sina Hospital of Rabat/Morocco, using two scales. One is a questionnaire containing most of the socio-demographic characteristics, and clinical characteristics. The second is the Dispositional Resilience Scale-15 (DRS15). Otherwise, our results indicate a relatively low rate of resilience of health staff practicing at Ibn Sina Hospital in Rabat/Morocco. 81\% of HCP have "low resilience", 16\% have shown "moderate resilience" and only $3 \%$ are in the "good resilience" range, based on analyzes of resilience scale results DSR15. The results of the DRS15 validation study indicate a positive correlation between engagement, control and challenge, as well as improved inter and intra-item correlation. Our study also indicates a statistically significant relationship between resilience and socio-economic difficulties of HCP. Sex, marital status, seniority, work schedule and medical history are risk factors. Indeed, women are more resilient than men, single people are more vulnerable than married couples, and new recruits are less resistant than older ones. In addition, the 12/36 continuous work schedule has a protective factor for HCP. These results go in the same direction as those found by some studies. Thus, the results of our study are encouraging and can be used for decision-making in this case.
\end{abstract}




\section{Keywords}

Psychological Resilience, Low Resilience, Health Care Professionals, Nurses, Physicians

\section{Introduction}

Occupational stress presents a major public health problem. It is the subject of many works in Morocco and in the world. Studies indicate that HCP are more exposed to occupational stress [1]-[6]. This phenomenon can disrupt the health of staff and the ability to adapt to their work. Indeed, the complexity of professional activities, the shortage of staff, the requirement of quality of care, emotional overload, role conflicts, noise make work in the hospital more painful and can increase vulnerability to stress [7]. In addition, many studies raise the effect of psychological resilience in the workplace by showing that in stressful working conditions, some people are effective and others have professional difficulties [8]. Psychological resilience is considered as a protective factor for stress effects and a style of functioning that includes cognitive and behavioral qualities [9]. Resistant individuals can cope with stress by actively coping with stressful situations, and less resilient people are more vulnerable and perceive stress as a generative threat of certain psychosomatic, cardiovascular and neuroendocrine diseases [10]-[18]. Psychological resilience includes three dimensions: control, commitment, and challenge. In fact, the control dimension is the belief in one's own ability to influence events through one's own efforts; commitment is the tendency to get involved in activities and to perceive events as interesting, while the challenge is to see change and new experiences as interesting opportunities for learning and development [19].

The main of this study is to establish the profile of psychological resilience and its relationship with certain risk factors, in a sample of HIS health staff in Rabat/Morocco.

\section{Population and Materials and Methods}

\subsection{Participants}

The study that we conducted is carried out on $230 \mathrm{HCP}$ ( 150 nurses and 80 doctors) belonging to the different services of Ibn Sina hospital of Rabat/Morocco, during the year 2016.

\subsection{Sampling Tools}

- A questionnaire containing most of the socio-demographic characteristics (age, sex, means of transport, work schedule system) and clinical characteristics (medical history) distributed to staff wishing to participate in this study.

- A second questionnaire of the Dispositional Resilience Scale-15 (DRS15) test [19] [20], offered to each respondent to study the psychological resilience. 
The test used to assess the personality resistant to stress. It consists of 15 items grouping together the three main factors of resilience: (1) Commitment: items 1, 4, 7, 10,13; the Control: items 2, 6, 8, 12, 15 and the Challenge: items $3,5,9,11,14$. The participants answer on a scale of four levels, corresponding to the veracity that each item has for them: 0 ("not true at all"), 1 ("a little true"), 2 ("quite true") and 3 ("absolutely right"). The total score obtained by performing the sum of the 15 items.

\subsection{Statistical Tools}

The collected data filtered and transferred to a statistical support. Correspondence analyzes and significance tests chosen to exploit this data. The results expressed as frequencies for the qualitative variables and as averages for the quantitative variables.

\section{Results}

\subsection{Socio-Demographic Characteristics of HCP}

Table 1 presents the socio-demographic and socio-economic characteristics of 230 HCP working in different departments of Ibn Sina Hospital in Rabat. However, $56.96 \%(\mathrm{n}=131)$ of the respondents are female and $42.86 \%(\mathrm{n}=99)$ male, so $65.2 \%(n=150)$ are nurses, $34.8 \%$ are doctors. The distribution of respondents by age shows that $76.52 \%(n=176)$ are between the ages of 25 and 55 (Gaussian distribution). 65.22\% $(\mathrm{n}=150)$ of these respondents are married. In addition, $41.74 \%(\mathrm{n}=96)$ work in the sector between 5 to 20 years compared to $30.87 \%$ who have less than five years of service and $27.39 \%$ with more than 20 years of service. On the other hand, $70.4 \%(n=162)$ responded to the "Regular means of transport" question by reaching the workplace by means of transport, compared with $29.6 \%(n=68)$ who reported join him on foot. With regard to the work schedule system followed by each respondent, $68.3 \%$ ( $n=157$ ) work according to the continuous work schedule, $17.4 \%(n=40)$ work in $12 / 36$ and $13 \%(n=30) 13.0 \%(n=30)$ evolve according to the normal time system.

Nevertheless, the distribution of respondents, according to their health states shows that $69.1 \%(n=159)$ answered that they do not suffer from any disease, $11.7 \%(n=27)$ of them confirm to suffer of arterial hypertension and 7 people who remain: 2 cases of cancer and 5 cases suffer from mental disorder

\subsection{Study of Dispositional Resilience Scale (DRS15)}

The study of DRS15 consists of evaluating three dimensions: commitment, control and challenge. In this part we will proceed to the separate analysis of these 3 factors.

\subsubsection{Validation Study of the DRS15 Test}

Table 2 summarizes the results of the descriptive analysis of inter/intra-item validation of the three dimensions of DRS15 by the calculation of Cronbach's Alpha in case of removal of the element. This table shows high fidelity 
Table 1. Socio-demographic characteristics of the respondents.

\begin{tabular}{|c|c|c|c|c|}
\hline \multirow{2}{*}{ Variable } & \multirow{2}{*}{ Modality } & \multicolumn{2}{|c|}{ Gender } & \multirow{2}{*}{ Total } \\
\hline & & Male & Female & \\
\hline \multirow[t]{2}{*}{ Grade } & Nurse & 64 & 86 & 150 \\
\hline & Doctor & 35 & 45 & 80 \\
\hline \multirow[t]{3}{*}{ Age in years } & Less to 25 & 8 & 21 & 29 \\
\hline & Between 25 and 55 & 75 & 101 & 176 \\
\hline & Upper to 55 & 16 & 9 & 25 \\
\hline \multirow[t]{2}{*}{ Marital status } & Single & 32 & 48 & 80 \\
\hline & Married & 67 & 83 & 150 \\
\hline \multirow[t]{3}{*}{ Seniority in years } & Less to 5 & 25 & 46 & 71 \\
\hline & Between 5 and 20 & 42 & 54 & 96 \\
\hline & Upper to 20 & 32 & 31 & 63 \\
\hline \multicolumn{2}{|c|}{ Total } & 99 & 131 & 230 \\
\hline
\end{tabular}

Table 2. Inter and intra-items validation of the three dimensions of DRS15.

\begin{tabular}{|c|c|c|c|c|c|c|}
\hline \multirow[b]{2}{*}{ Item } & \multicolumn{2}{|c|}{ Commitment } & \multicolumn{2}{|c|}{ Control } & \multicolumn{2}{|c|}{ Challenge } \\
\hline & Mean \pm SD & $\begin{array}{c}\text { Alpha of } \\
\text { Cronbach } \\
\text { after } \\
\text { suppression } \\
\text { of item }\end{array}$ & Mean \pm SD & $\begin{array}{c}\text { Alpha of } \\
\text { Cronbach } \\
\text { after } \\
\text { suppression } \\
\text { of item }\end{array}$ & Mean \pm SD & $\begin{array}{c}\text { Alpha of } \\
\text { Cronbach } \\
\text { after } \\
\text { suppression } \\
\text { of item }\end{array}$ \\
\hline Item 1 & $1.81 \pm 0.95$ & 0.52 & - & - & - & - \\
\hline Item 4 & $0.66 \pm 0.99$ & 0.53 & - & - & - & - \\
\hline Item 7 & $2.01 \pm 0.89$ & 0.47 & - & - & - & - \\
\hline Item 10 & $1.74 \pm 0.93$ & 0.52 & - & - & - & - \\
\hline Item 13 & $0.86 \pm 0.98$ & 0.51 & - & - & - & - \\
\hline Item 2 & - & - & $1.83 \pm 1.01$ & 0.48 & - & - \\
\hline Item 6 & - & - & $1.95 \pm 0.94$ & 0.46 & - & - \\
\hline Item 12 & - & - & $0.83 \pm 1$ & 0.47 & - & - \\
\hline Item 15 & - & - & $1.68 \pm 1.1$ & 0.49 & - & - \\
\hline Item 8 & - & - & $0.80 \pm 0.98$ & 0.52 & - & - \\
\hline Item 5 & - & - & - & - & $2.49 \pm 0.90$ & 0.51 \\
\hline Item 9 & - & - & - & - & $1.59 \pm 1.04$ & 0.48 \\
\hline Item 3 & - & - & - & - & $0.81 \pm 1.00$ & 0.50 \\
\hline Item 11 & - & - & - & - & $1.21 \pm 1.09$ & 0.49 \\
\hline Item 14 & - & - & - & - & $1.34 \pm 1.14$ & 0.53 \\
\hline
\end{tabular}

and intra/inter-item compatibility as long as the values of the alpha after deletion become lower than the average Cronbach value of 0.82 . 
Nevertheless, for the "commitment" dimension, items 1 "I spend most of my time doing things that are useful or meaningful to me", 7 "I look forward to doing my professional activities" and 10 "most of the time, I find my life interesting thrilling" have posted average scores close to 2 , this score corresponds to a level of scale "quite true". However items 4 "I feel that my life is somehow not very useful or meaningless" and 13 "Generally, life seems boring" recorded means close to 1 which corresponds to a level "A little real".

Regarding the "control" dimension, 3 items out of 5 had average scores close to 2 (quite true level), these items are 2 "Working hard, you can almost always achieve your goals", 6 "The course of my life depends on my own actions", 15 "My own choices have a real influence on the unfolding of the events I live". Items 8 "I do not think I can do much to influence my future" and 12 "It's up to me to decide what will be the rest of my life" have average scores close to 1 (level a little bit true).

For the challenge dimension, we noted a variation in the responses of items in this dimension. However, the average scores of items 11 "It bothers me when my daily routine is interrupted", 14 "I like having a schedule that does not change too much" and 3 "I do not like to make changes in my activities are close to 1 ", this value corresponds to a wish level (not very true). However, item 9 "I like the challenge of doing more than one task at a time" had a mean score of 1.6 which corresponds to a level 2 , then item 5 "J like to change the daily routine", displays an average score close to 3 which is associated a level (quite true).

\subsubsection{Global Study of the Three Dimensions}

Table 3 presents the results of the multiple correlation between the three dimensions taken 2 to 2 . This table shows a very highly significant and positive sign correlation between the commitment and the control $(r=+0.349)$ of a share and between commitment and challenge on the other hand $(r=+0.233)$. Therefore deduces a strong significant connection between the control and the challenge ( $r$ $=+0.321$ ). Indeed, the correlation between commitment, control and challenge, and the total score is very strong with correlation coefficients of $+0.68 ;+0.78$ and +0.72 .

\subsection{Study of Relationship between Categories and Socio-Economic Factors}

The categories of levels of psychological resilience to stress were deduced by the method corresponding to the percentile: the 25th percentile corresponds to the average score of 27 and the 75th percentile corresponds to the average score of 33. All faith, the distribution of respondents according to the Resilience category shows that $81.30 \%$ of caregivers have low resilience and $2.61 \%$ develop high resilience. However, $16.09 \%$ of respondents expressed moderate resilience, so this category of caregivers may be highly resilient or may become a low resilience category. Table 4 expresses the results of the association of the degree of resilience and certain socio-demographic factors. This analysis shows that of all 
Table 3. Multiple correlation of the three dimensions.

\begin{tabular}{ccccc}
\hline & Commitment & Control & Challenge & TOTAL \\
\hline Commitment & 1 & $0.349^{* *}$ & $0.233^{* *}$ & $0.681^{\star *}$ \\
& & 0.000 & 0.000 & 0.000 \\
Control & $0.349^{* *}$ & 1 & $0.321^{* *}$ & $0.783^{* *}$ \\
& 0.000 & & 0.000 & 0.000 \\
Challenge & $0.233^{* *}$ & $0.321^{* *}$ & 1 & $0.725^{* *}$ \\
& 0.000 & 0.000 & & 0.000 \\
TOTAL & $0.681^{* *}$ & $0.783^{* *}$ & $0.725^{* *}$ & 1 \\
& 0.000 & 0.000 & 0.000 & 230 \\
\hline
\end{tabular}

Table 4. Relation between socio-demographic variables and DRS15 scale.

\begin{tabular}{|c|c|c|c|c|c|c|}
\hline \multirow{2}{*}{ Variable } & \multirow{2}{*}{ Modality } & \multicolumn{3}{|c|}{ DRS-15 } & \multirow{2}{*}{ Total } & \multirow[t]{2}{*}{ chi- 2} \\
\hline & & Law & Average & High & & \\
\hline \multirow[t]{2}{*}{ Gender } & Male & 83 & 16 & 0 & 99 & $6.89(\mathrm{p}<0.032)^{*}$ \\
\hline & Female & 104 & 21 & 6 & 131 & \\
\hline \multirow[t]{2}{*}{ Grade } & Nurse & 123 & 25 & 2 & 150 & $2.80(\mathrm{p}<0.25) \mathrm{ns}$ \\
\hline & Doctor & 64 & 12 & 4 & 80 & \\
\hline \multirow[t]{3}{*}{ Age } & $<25$ & 21 & 8 & 0 & 29 & $10.16(\mathrm{p}<0.25) \mathrm{ns}$ \\
\hline & $25<>55$ & 148 & 22 & 6 & 176 & \\
\hline & $>55$ & 18 & 7 & 0 & 25 & \\
\hline \multirow[t]{2}{*}{ Marital status } & Single & 64 & 14 & 2 & 80 & $11.05(\mathrm{p}<0.05)^{*}$ \\
\hline & Married & 123 & 23 & 4 & 150 & \\
\hline \multirow[t]{3}{*}{ Seniority } & $<5$ & 60 & 10 & 1 & 71 & $7.50(\mathrm{p}<0.047)^{*}$ \\
\hline & $5<>20$ & 82 & 11 & 3 & 96 & \\
\hline & $>20$ & 45 & 16 & 2 & 63 & \\
\hline \multirow[t]{2}{*}{ Transport tools } & Auto & 132 & 24 & 4 & 160 & $0.53(\mathrm{p}<0.93)$ \\
\hline & By foot & 55 & 13 & 2 & 70 & \\
\hline \multirow[t]{3}{*}{ Hour of work } & $12 / 36$ & 31 & 8 & 1 & 40 & $2.43(\mathrm{p}<0.05)^{*}$ \\
\hline & Continue & 127 & 25 & 5 & 157 & \\
\hline & Normal & 26 & 4 & 0 & 30 & \\
\hline \multirow[t]{4}{*}{ Antecedent } & None & 134 & 21 & 4 & 159 & $8.80(\mathrm{p}<0.041)^{*}$ \\
\hline & HT & 21 & 6 & 0 & 27 & \\
\hline & Cancer & 2 & 0 & 0 & 2 & \\
\hline & Psychologic & 3 & 1 & 1 & 5 & \\
\hline Total & & 187 & 37 & 6 & 230 & \\
\hline
\end{tabular}

Law (<27); Average (28<> 33); high (>34); ns: not significant difference; s: significant difference. 
the variables tested, sex, marital status, seniority, work schedule, and antecedents are risk factors for stress resilience.

○ The chi-square test shows strong binding between sex and DRS15 (chi-square $=6.89, \mathrm{p}<0.032)$. However, $83.84 \%(\mathrm{n}=83)$ of men are low resilient compared to $79.39 \%(n=104)$ of females. However, $16.16 \%$ of males and $16.03 \%$ of females expressed moderate resilience. In addition, 6 women and 0 men developed a strong resilience to stress.

○ Marital status was associated with DRS15 (chi-square $=11.05, \mathrm{p}<0.05$ ). In fact, the rate of singles with low resilience is $82 \%$ and that of the groom is $80 \%$. However, of the 6 respondents who showed strong resistance, 4 cases are married and 2 cases are single.

- With respect to the seniority factor expressed as the number of years of exercise, the chi-square test showed a significant relationship with the DRS15 (chi-square $=7.50, \mathrm{p}<0.047$ ). Moreover, of all the people who have developed a low resilience, $84.51 \%$ have a seniority of less than 5 years, $85.42 \%$ have a seniority of 5 to 20 and $71.43 \%$ have a seniority of more than 20 years.

○ Work schedule is a critical factor in stress resilience (significant chi-square). In fact, the distribution of persons who have developed a low resistance to stress according to the work schedule shows that $86.67 \%$ work according to the normal work schedule system, 80.89 work according to the continuous work schedule system and $77.50 \%$ work. \% chose the $12 / 36$ work system. However, $20 \%$ of those with moderate resistance work in the $12 / 36$ system compared to $15.92 \%$ and $13 \%$, respectively, for the categories working in the continuous and normal systems.

- Regarding the antecedents of the respondent's health status, the chi-square test showed a strong relationship with DRS15 (chi-square $=8.80, \mathrm{p}<0.04$ ). However, out of 159 people who answered that they do not suffer from any disease, 134 showed a weak resistance. In addition, 21 of 27 caregivers with hypertension are low in resistance to stress. The other cancer and psychic illnesses all showed weak resistance.

\section{Discussion}

Psychological resilience is a force of hardiness that enables people to cope positively with stressful situations [9]. It contributes to improvement, despite the presence of stressful circumstances, performance and health [21]. This study shows numerous results that contribute to the understanding of the concepts developed by the highly resilient respondents. In addition, our results indicate a relatively low rate of resilience of health staff practicing at Ibn Sina Hospital in Rabat/Morocco. An $81 \%$ of caregivers have "low resilience", 16\% have shown "moderate resilience" and only 3\% are in the "good resilience" range, based on analyses of resilience scale results DSR15 [19]. With regard to the surveyed population, we included in this study doctors and nurses because according to the literature, are the most affected professions by occupational stress [1] [2] [3]. 
Our study, is one of the first Moroccan studies that deals with the assessment of the psychological resilience of HCP in hospitals. However, we used the dispositional resilience scale to evaluate the various components of the state of hardiness including engagement, control, and challenge to provide an effective tool for identifying the psychological resilience of HCP.

The results of the DRS15 validation study indicate a positive correlation between engagement, control and challenge, as well as improved inter/intra-item correlation. This allows us to draw the idea that the stress-resistant personality of carers understands three dimensions intimately linked to each other: "commitment, control and challenge". indeed, engagement allows to get involved in the work and to adapt positively in the professional context whereas the control dimension contains elements of cognitive evaluation of choices, objectives, actions and decisions and the challenge factor reflects the involvement of HCP in the process of change [19] [20].

Returning to studies that have been done, the resilience of HCP is a protective factor to the detrimental effects of work-related stress [22]. Resilient people can cope positively with stressful events, but vulnerable perceive the stressful situation as threatening, reject change and prefer stability [23].

As a protective factor [24], psychological resilience allows staff to become actively involved in their work environment and demonstrates that they are able to cope with stress, leaving less stressful experiences [10]. In addition, harder workers consciously integrate commitment, control and challenge by using cognitive and behavioral tools to solve problems, make decisions, and manage difficulties and set goals, while quickly dealing with stressful situations.

Our study also indicates a statistically significant relationship between resilience and socio-economic difficulties of HCP. Sex, marital status, seniority, work schedule and antecedents are risk factors. Indeed, women are more resilient than men, single people are more vulnerable than married couples, and new recruits are less resistant than older ones. In addition, the 12/36 continuous work schedule has a protective factor for HCP. These results go in the same direction as those found by some studies. Resilience not only influences stress responses, but can also lead to different data and experiences [25].

A study of soldiers participating in peacekeeping operations showed that those who were more resilient could find more meaning in their activities, which, after their cessation, had certain advantages, for example a better personal experience and better ability to overcome situations [26]. Strong linkage associates the presence of diseases and resilience has been confirmed. This result is consistent with that of Hystad, Eid and Brevik [27], these authors have shown the potential effects of psychological resilience on people's HCP.

Another research on workplace injuries suggests that participants who are more resistant are less likely to become ill and suffer fewer injuries requiring hospitalization [28]. This allows us to confirm that psychological resilience is a determining factor of well-being at work [29]. In addition, we also found that married subjects are more resilient than single people. This allows us to assume 
that conjugal life can provide psychological and social support in situations of occupational stress [30]. Thus, resilient people are ambitious, accept change, see their work better and are more attached to their organization [31].

\section{Conclusion}

At the end of this work on the psychological resilience of HCP, the level of resilience is low at $81.30 \%$, moderate at $16.09 \%$, and high at only $2.61 \%$ of them. This correlates strongly with the good resilience to stress in our sample. In addition, seniority, work schedule and antecedents are risk factors for altering the stress resilience of HCP.

\section{References}

[1] Laurent, A., Chahraoui, K. and Carli, P. (2007) Les répercussions psychologiques des interventions médicales urgentes sur le personnel SAMU. Étude portant sur 50 intervenants SAMU. In: Annales Médico-psychologiques, revue psychiatrique, 165, 570-578. https://doi.org/10.1016/j.amp.2005.06.011

[2] Goldberg, D.P. (1988) User's Guide to the General Health Questionnaire. NFER-Nelson, Windsor.

[3] Jehel, L. (2002) Victimes et soignants face au traumatisme psychique: Etudes de facteurs prédictifs péritraumatiques et validations d'instruments de mesures. Doctoral dissertation, Paris 6.

[4] ElAmri, I., Allouche, W., Benali, B. and ElKholti, A. (2016) Évaluation du burnout chez le personnel soignant au niveau du service d'accueil des urgences du CHU Ibn Rochd. Archives des Maladies Professionnelles et de I Environnement, 77, 560. https://doi.org/10.1016/j.admp.2016.03.480

[5] Massou, S., Doghmi, N., Belhaj, A., Aboulaala, K., Azendour, H., Haimeur, C. and Kamili, N.D. (2013) Enquête sur le syndrome d'épuisement professionnel chez les personnels d'anesthésie réanimation de quatre hôpitaux universitaires marocains. Annales Médico-psychologiques, revue psychiatrique, 171, 538-542. https://doi.org/10.1016/j.amp.2012.02.024

[6] Laurent, A. and Chahraoui, K. (2012) L'impact du stress professionnel sur les intervenants SMUR. Pratiques psychologiques, 18, 413-428. https://doi.org/10.1016/j.prps.2010.11.003

[7] Gray-Toft, P. and Anderson, J.G. (1981) The Nursing Stress Scale: Development of an Instrument. Journal of Behavioral Assessment, 3, 11-23. https://doi.org/10.1007/BF01321348

[8] Maddi, S.R. and Kobasa, S.C. (1984) Hardy Executive. Dow Jones-Irwin, Homewood, IL.

[9] Kobasa, S.C. (1979) Stressful Life Events, Personality, and Health: An Inquiry into Hardiness. Journal of Personality and Social Psychology, 37, 1. https://doi.org/10.1037/0022-3514.37.1.1

[10] Maddi, S.R. (1990) Issues and Interventions in Stress Mastery. In: Friedman, H.S., Ed., Personality and Disease, John Wiley \& Sons, New York, 121-154.

[11] Maddi, S.R. (1999) Comments on Trends in Hardiness Research and Theorizing. Consulting Psychology Journal: Practice and Research, 51, 67-71. https://doi.org/10.1037/1061-4087.51.2.67

[12] Nivet, P., Alby, J.M. and Crocq, L. (1989) Les réactions émotionnelles chez les déci- 
deurs, les sauveteurs et les soignants. Soins Psychiatrie, 106, 18-22.

[13] Steptoe, A. and Kivimäki, M. (2012) Stress and Cardiovascular Disease. Nature Reviews Cardiology, 9, 360-370. https://doi.org/10.1038/nrcardio.2012.45

[14] Kivimäki, M., Leino-Arjas, P., Luukkonen, R., Riihimäi, H., Vahtera, J. and Kirjonen, J. (2002) Work Stress and Risk of Cardiovascular Mortality: Prospective Cohort Study of Industrial Employees. BMJ, 325, 857. https://doi.org/10.1136/bmj.325.7369.857

[15] Yusuf, S., Hawken, S., Ounpou, S., et al. (2004) Effect of Potentially Modifiable Risk Factors Associated with Myocardial Infarction in 52 Countries. (The Interheart Study) A Case-Control Study. The Lancet, 364, 937-952. https://www.ncbi.nlm.nih.gov/pubmed/15364185 https://doi.org/10.1016/S0140-6736(04)17018-9

[16] Bernard, B.P. and Putz-Anderson, V. (1997) Musculoskeletal Disorders and Workplace Factors; A Critical Review of Epidemiologic Evidence for Work-Related Musculoskeletal Disorders of the Neck, Upper Extremity, and Low Back.

[17] Soulairac, A., Tuchmann-Duplessis, H. and Soulairac, M. (1992) Le bruit: Aspects neuro-endocriniens. Discussion. Bulletin de I Académie nationale de médecine, 176, 401-405.

[18] Azzaoui, F.Z., Chtibi, H., Ahami, A. and Hami, H. (2014) Preliminary Study of Distress among Medical and Paramedical Staff of Moroccan Hospital. Occupational and Environmental Medicine, 71, A117-A117.

https://doi.org/10.1136/oemed-2014-102362.367

[19] Bartone, P.T. (1999) Hardiness Protects against War-Related Stress in Army Reserve Forces. Consulting Psychology Journal: Practice and Research, 51, 72-82. https://doi.org/10.1037/1061-4087.51.2.72

[20] Bartone, P.T., Ursano, R.J., Wright, K.M. and Ingraham, L.H. (1989) The Impact of a Military Air Disaster on the Health of Assistance Workers. Journal of Nervous and Mental Disease, 177, 317-328. https://doi.org/10.1097/00005053-198906000-00001

[21] Maddi, S.R., Khoshaba, D.M., Persico, M., Lu, J., Harvey, R. and Bleecker, F. (2002) The Personality Construct of Hardiness: II. Relationships with Comprehensive Tests of Personality and Psychopathology. Journal of Research in Personality, 36, 72-85. https://doi.org/10.1006/jrpe.2001.2337

[22] Simoni, P.S. and Paterson, J.J. (1997) Hardiness, Coping, and Burnout in the Nursing Workplace. Journal of Professional Nursing, 13, 178-185. https://doi.org/10.1016/S8755-7223(97)80069-5

[23] Maddi, S.R. and Hightower, M. (1999) Hardiness and Optimism as Expressed in Coping Patterns. Consulting Psychology Journal: Practice and Research, 51, 95-105. https://doi.org/10.1037/1061-4087.51.2.95

[24] Walton, S.J. (1990) Stress Management Training for Overseas Effectiveness. International Journal of Intercultural Relations, 14, 507-527. https://doi.org/10.1016/0147-1767(90)90033-S

[25] Wiebe, D.J. and Williams, P.G. (1992) Hardiness and Health: A Social Psychophysiological Perspective on Stress and Adaptation. Journal of Social and Clinical Psychology, 11, 238-262. https://doi.org/10.1521/jscp.1992.11.3.238

[26] Britt, T.W., Adler, A.B. and Bartone, P.T. (2001) Deriving Benefits from Stressful Events: The Role of Engagement in Meaningful Work and Hardiness. Journal of Occupational Health Psychology, 6, 53-63. https://doi.org/10.1037/1076-8998.6.1.53 
[27] Hystad, S.W., Eid, J. and Brevik, J.I. (2011) Effects of Psychological Hardiness, Job Demands, and Job Control on Sickness Absence: A Prospective Study. Journal of Occupational Health Psychology, 16, 265-278. https://doi.org/10.1037/a0022904

[28] Greene, R.L. and Nowack, K.M. (1995) Hassles, Hardiness and Absenteeism: Results of a 3-Year Longitudinal Study. Work \& Stress, 9, 448-462. https://doi.org/10.1080/02678379508256892

[29] Cash, M.L. and Gardner, D. (2011) Cognitive Hardiness, Appraisal and Coping: Comparing Two Transactional Models. Journal of Managerial Psychology, 26, 646-664. https://doi.org/10.1108/02683941111181752

[30] Sezgin, F. (2009) Relationships between Teacher Organizational Commitment, Psychological Hardiness and Some Demographic Variables in Turkish Primary Schools. Journal of Educational Administration, 47, 630-651.

https://doi.org/10.1108/09578230910981099

[31] McCalister, K.T., Dolbier, C.L., Webster, J.A., Mallon, M.W. and Steinhardt, M.A. (2006) Hardiness and Support at Work as Predictors of Work Stress and Job Satisfaction. American Journal of Health Promotion, 20, 183-191.

https://doi.org/10.4278/0890-1171-20.3.183 